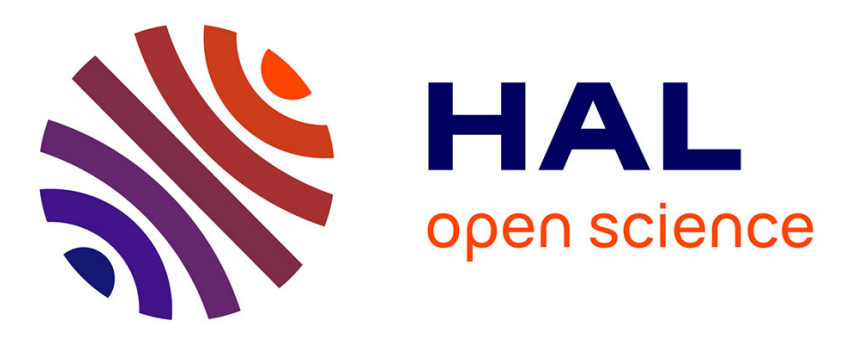

\title{
Design and optical characterization of a large continuous phase-plate for Laser Integration Line and Laser Megajoule facilities
}

\author{
Jerome Neauport, Xavier Ribeyre, Jerome Daurios, Denis Valla, Martine \\ Lavergne, Vincent Beau, Laurent Videau
}

\section{To cite this version:}

Jerome Neauport, Xavier Ribeyre, Jerome Daurios, Denis Valla, Martine Lavergne, et al.. Design and optical characterization of a large continuous phase-plate for Laser Integration Line and Laser Megajoule facilities. Applied optics, 2003, pp.2377-2382. 10.1364/AO.42.002377 . cea-01053380

\section{HAL Id: cea-01053380 https: / hal-cea.archives-ouvertes.fr/cea-01053380}

Submitted on 30 Jul 2014

HAL is a multi-disciplinary open access archive for the deposit and dissemination of scientific research documents, whether they are published or not. The documents may come from teaching and research institutions in France or abroad, or from public or private research centers.
L'archive ouverte pluridisciplinaire HAL, est destinée au dépôt et à la diffusion de documents scientifiques de niveau recherche, publiés ou non, émanant des établissements d'enseignement et de recherche français ou étrangers, des laboratoires publics ou privés. 


\title{
Design and optical characterization of a large continuous phase plate for Laser Integration Line and laser Megajoule facilities
}

\author{
Jérôme Néauport, Xavier Ribeyre, Jérôme Daurios, Denis Valla, Martine Lavergne, \\ Vincent Beau, and Laurent Videau
}

\begin{abstract}
For development of the French Laser Integration Line and the Laser Megajoule, we describe the design and the control of a first $383 \mathrm{~mm} \times 398 \mathrm{~mm}$ continuous phase-plate prototype. Extensively used in laser fusion facilities for beam smoothing, this optical component was manufactured by deep etching onto a fused-silica substrate, which led to a phase plate engraved directly onto fused silica, with which good optical performance could be achieved. We demonstrate good agreement between the desired simulated component and the manufactured component in terms of focal spot shape. This demonstration was performed by both interferometric and photometric measurements. (c) 2003 Optical Society of America

OCIS codes: $140.3300,220.4840,120.3180,120.5240$.
\end{abstract}

\section{Introduction}

Large laser facilities, such as the Laser Integration Line (LIL), the Laser Megajoule (LMJ), ${ }^{1}$ or the $\mathrm{Na}$ tional Ignition Facility, ${ }^{2}$ nominally produce focal spots of important size, an order of magnitude beyond the diffraction limit. Moreover the focal spot includes hot spots that are due mainly to the aberrations of the important number of large-size optical components used on each laser line (40 components for LIL and LMJ). An indirect drive-fusion-class laser needs to deliver a focal spot that limits parametric instabilities of the produced plasma (Raman and Brillouin backscattering). Several smoothing techniques were developed for this purpose. Use of a random-phase element for this purpose was first introduced by Kato et al. ${ }^{3}$ A binary two-level $(0, \pi)$ random-phase plate $(\mathrm{RPP})$ with regular rectangular elements was placed in the plane of the last focusing component of the laser. This RPP created an intensity distribution in the focal plane of the overall envelope equal to the Fourier transform of the

The authors are with the Commissariat à l'Energie Atomique, Centre d'Etudes Scientifiques et Techniques d'Aquitaine, 33114 Le Barp Cedex, France. J. Néauport's e-mail address is jerome. neauport@cea.fr.

Received 20 September 2002; revised manuscript received 9 January 2003.

0003-6935/03/132377-06\$15.00/0

(C) 2003 Optical Society of America elementary rectangular element of the RPP. This envelope was filled with a speckle pattern introduced by the random distribution of rectangular elements of the RPP. The speckle pattern can be additionally rapidly moved during laser pulse duration, which can be done by an enlargement of the laser spectrum and the introduction of a dispersive element in the laser such as a grating. ${ }^{4,5}$ A combination of broad spectrum, phase plate, and dispersive element is referred to as smoothing by spectral dispersion and it is basically the smoothing principle that was chosen for the LIL and the LMJ. Figure 1 shows the final optics design of the LIL and the LMJ. ${ }^{6}$ A broad spectrum is generated by a sinusoidal phase modulator placed in the front end of the laser. After frequency conversion, the $0.351-\mu \mathrm{m}$ converted light is focused by the $3 \omega$ grating lens ${ }^{7,8}$ onto the target. Smoothing is ensured by both the $3 \omega$ grating lens that serves as a chromatic lens to introduce dispersion along the propagation axis (longitudinal smoothing) and by a phase plate placed $1.25 \mathrm{~m}$ behind the vacuum window of the focusing grating. To the best of our knowledge, this is the first time that this smoothing principle is used.

Since Kato et al..$^{3}$ introduced the use of a randomphase element in 1994, much progress has been made in the field of phase-plate design. Woods et al. ${ }^{9}$ and Dixit et al. ${ }^{10}$ replaced the rectangular elements by hexagonal elements, thus improving the theoretical efficiency of the phase plate from $81.5 \%$ to $84 \%$. In an attempt to gain some efficiency and better control 


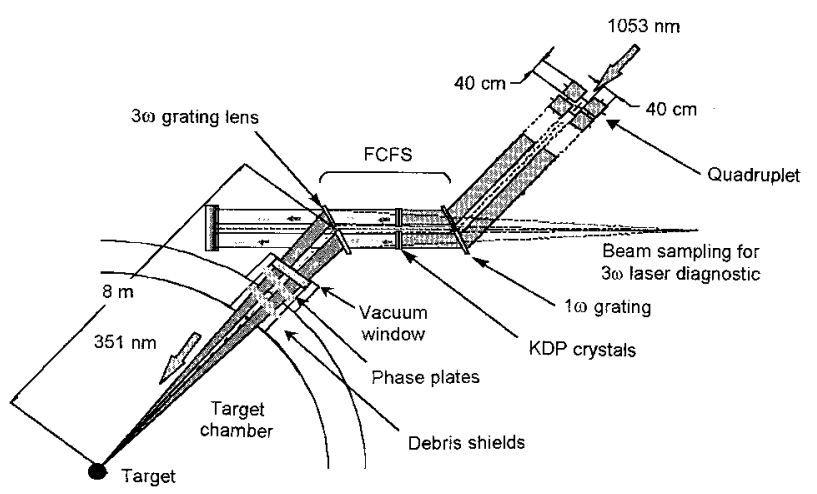

Fig. 1. First-come, first-serve frequency conversion and focusing system (FCFS) optical setup.

of the focal spot shape, the principle of a multilevel (16 levels) phase plate was proposed by Thomas et al. ${ }^{11,12}$ Such phase plates, known as kinoform phase plates, allow us to couple theoretically $95 \%$ of the energy in the desired area and an almost flat-top high-order super-Gaussian envelope. The design of a continuous phase plate (CPP) with a strict continuous profile leads to a theoretical efficiency of $100 \%$ with a high-order super-Gaussian focal spot envelope. ${ }^{13}$ This last type of phase plate was retained by the Commissariat à l'Energie Atomique (CEA) to equip the LIL and the LMJ facilities because of its high efficiency and flexibility.

Here we present the developments that we achieved to calculate, manufacture, and control the LIL and the LMJ phase plates. The CPP involved numerical developments, and the adopted solutions are presented in Section 2. Etching of the phase profile onto a fused-silica substrate was manufactured by Jobin Yvon at the request of the CEA. The first prototype (99-0148) was delivered by Jobin Yvon in late 2001. Metrological issues of this prototype, including an original method of wave-front measurements by stitching interferometry and direct photometric focal spot measurements, are detailed in Section 3.

\section{Phase Profile Calculation and Focal Spot Specification}

As mentioned above, to gain good energy efficiency we designed a CPP. Here we present the algorithm based on the Gerchberg-Saxton ${ }^{14}$ iterative algorithm. Figure 2 shows a schematic flow that can be used to obtain a continuous phase. The phase screen is iteratively improved by the repeated propagation between the near-field and the far-field planes and application of the near-field and the farfield constraints at each iteration step. This algorithm allows us to generate a phase screen to design a high-order super-Gaussian focal plane irradiance profile. It is possible to generate a far-field profile with a higher order than a 10th power superGaussian. The principal difficulties of this calculation method is the choice of an initial phase condition and the number of iterations to keep a wrapped phase

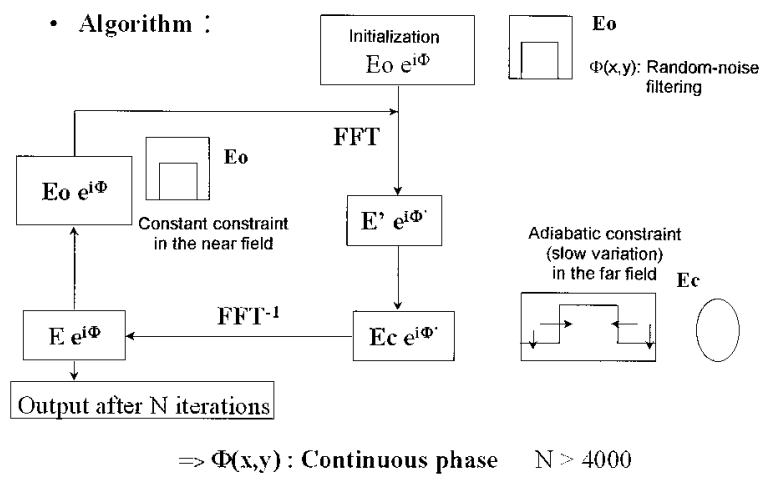

Fig. 2. Schematic of the flow of the Gerchberg-Saxton iterative algorithm for the design of CPPs.

screen. We solved the latter problem by choosing an adiabatic modification of the far-field profile when we used the iterative algorithm. To control the flatness of the focal spot is also difficult. To remove the deformation of the flattop we used a posttreatment that consists of some additional iteration of the algorithm with a far-field mask modified to compensate the exact focal spot flat-top deformation. For the calculation we used $256 \times 256$ pixels and 4000 iterations. The time and the memory that we used on a DEC Alpha Station were approximately $40 \mathrm{~min}$ and 20 Mbytes, respectively. Figures 3(a) and 3(b) show,
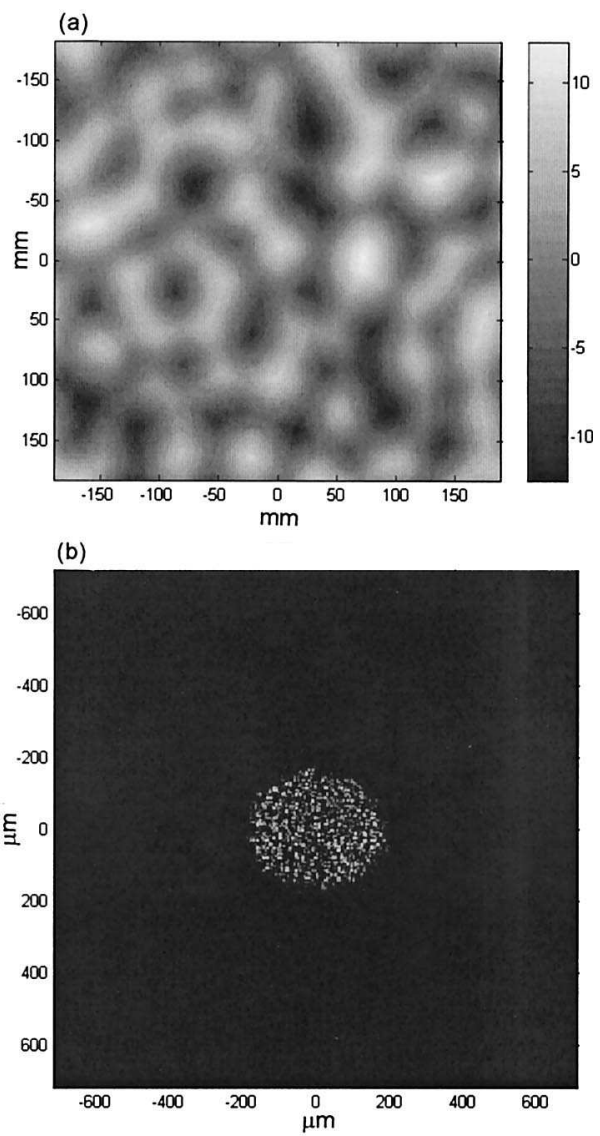

Fig. 3. (a) Calculated phase profile in radians. (b) Associated focal spot. 
Table 1. Focal Spot Specifications

\begin{tabular}{lc}
\hline \multicolumn{1}{c}{ Parameter } & Specification \\
\hline Ellipticity & $0.90 \pm 0.10$ \\
Diameter (small axis) at $1 / e I_{0}(\mu \mathrm{m})$ & $330 \pm 20$ \\
Diameter (small axis) at $10 \% I_{0}(\mu \mathrm{m})$ & $370 \pm 25$ \\
Diameter (small axis) at $3 \% I_{0}(\mu \mathrm{m})$ & $400 \pm 50$ \\
\hline
\end{tabular}

respectively, the result of phase calculation for a circular focal spot and the corresponding focal spot. To control the shape of the focal spot it is important to define all the spot parameters. First, we calculated the average intensity $\left(I_{0}\right)$ at the top of the focal spot; second, we calculated the size of the focal spot at $1 / e$ of $I_{0}, 10 \%$ of $I_{0}, 3 \%$ of $I_{0}$, and the focal spot ellipticity. We also obtained the size at $1 / e$ and the order of a super-Gaussian fit of the focal spot. The specified parameters are listed in Table 1.

\section{Phase-Plate Characterization}

The issue was to evaluate the optical performance quality of the 99-0148 prototype phase plate and therefore the agreement of the engraved profile to the specified profile. Two types of metrology were initiated for this purpose: photometric-based and interferometric-based measurements.

\section{A. Focal Spot Measurement}

The focal spot delivered by the manufactured phase plate was measured by use of the optical setup depicted in Fig. 4. The $383 \mathrm{~mm} \times 398 \mathrm{~mm}$ phase plate was placed at $1.25 \mathrm{~m}$ in the first transmitted order of an 8-m focal-length LIL $3 \omega$ focusing grating. ${ }^{7}$ The grating operates at $25^{\circ}$ and measures $420 \mathrm{~mm} \times 470$ $\mathrm{mm}$. This setup is equivalent to the on-line position of the optical component on the LIL. The focusing grating is illuminated with an almost plane wave front delivered by a large $420 \mathrm{~mm} \times 420 \mathrm{~mm}$ square collimator at 351.1-nm wavelength. The collimator consists of a large $460 \mathrm{~mm} \times 460 \mathrm{~mm}$ off-axis parabola with a clear aperture of $420 \mathrm{~mm} \times 420 \mathrm{~mm}$. The focal distance and the off-axis distance of the parabola are, respectively, $4.5 \mathrm{~m}$ and $300 \mathrm{~mm}$. The residual aberrations of the parabola's surface are estimated by interferometric measurement at $80-\mathrm{nm}$ peak to valley (p.v.). The parabola was illuminated by an optical fiber by means of an argon laser (Coherent Innova $308 \mathrm{C}$ ). The optical fiber, which was positioned at the focal point of the parabola, delivered $400-\mathrm{mW}$ light at 351.1-nm wavelength. The sogenerated plane wave-front is directed toward the

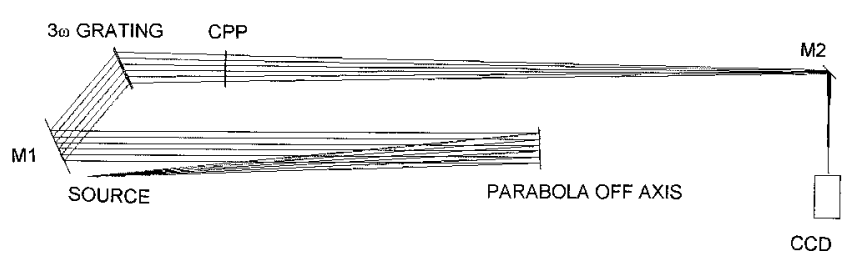

Fig. 4. Focal spot control setup. (a)
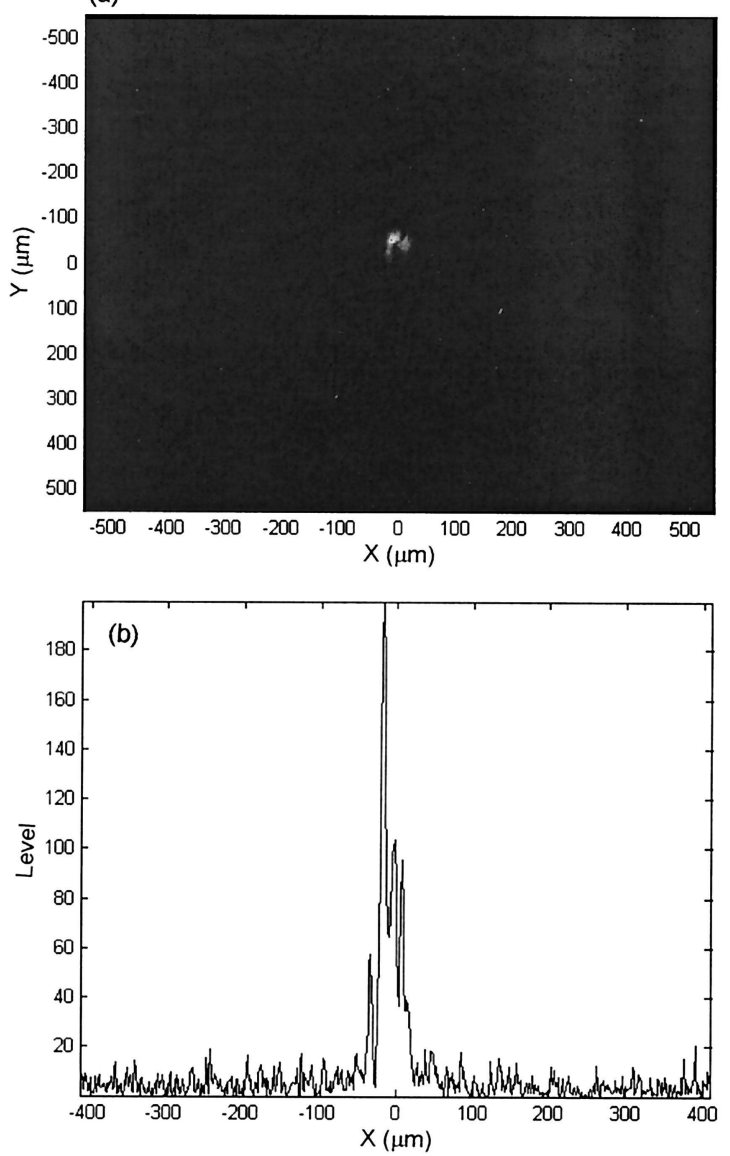

Fig. 5. (a) Image delivered by the 8-m focal-length focusing grating illuminated with a plane wave front at 351-nm wavelength. (b) Plot of the central portion of the image.

focusing grating by a large $610 \mathrm{~mm} \times 430 \mathrm{~mm}$ mirror (M1) with a clear aperture of $592 \mathrm{~mm} \times 420 \mathrm{~mm}$ manufactured of Sitall glass. The optical reflected wave-front quality of the mirror was measured by interferometry at $67 \mathrm{~nm}$ p.v., 9 -nm rms at an operating angle of incidence of $25^{\circ}$. A smaller second mirror of equivalent quality was used to deflect the focused beam to the camera. The quality of the wave front delivered to the grating by the parabola and the M1 mirror is estimated at $\lambda$ p.v. at $633 \mathrm{~nm}$ on a $420 \mathrm{~mm} \times 420 \mathrm{~mm}$ aperture. The focal spot delivered by this optical system is measured at the best-focus plane with a Hamamatsu ORCA II CCD 12 bit $1280 \times 1024$ camera optimized to operate at 351-nm wavelength. The camera is equipped with a microscope objective corrected to $351 \mathrm{~nm}$, so that the pixel delivered by the camera is equivalent to 1.36 $\mu \mathrm{m} \times 1.36 \mu \mathrm{m}$ in the measurement plane.

Figure 5(a) shows the CCD acquisition taken without a phase plate; a line portion of this CCD image is shown in Fig. 5(b). The energy distribution corresponds to the contribution of both focusing grating and collimator residual aberrations. After setting the CPP prototype at $1.25 \mathrm{~m}$ of the grating, the energy distribution observed at the best-focus plane is 
(a)
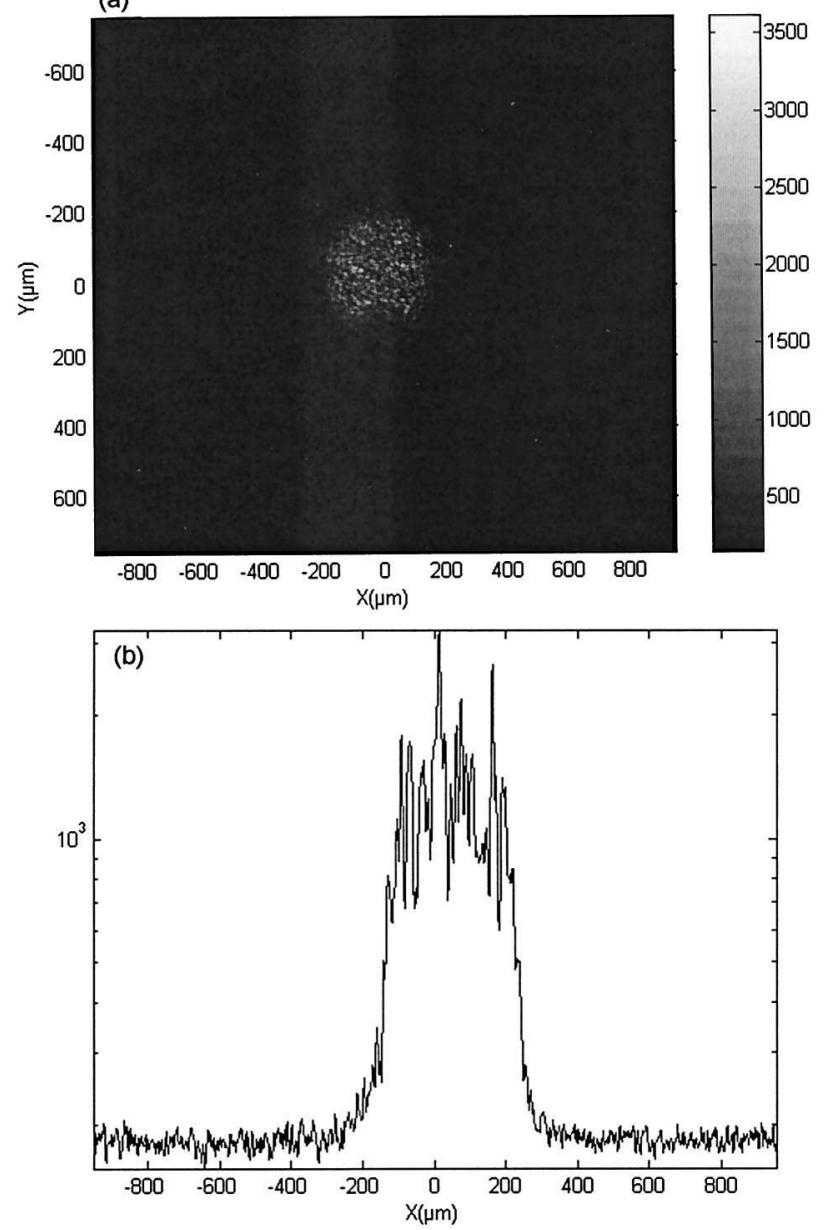

Fig. 6. (a) Image delivered by the CPP positioned 1.25 from the focusing grating. (b) Plot of the central portion of the image (log scale).

depicted in Fig. 6(a); a line plot of the central portion of the image is shown in Fig. 6(b). This focal spot was analyzed and fitted with a super-Gaussian irradiance profile. The result of this analysis is presented in Table 2 and compared with the specifications. Data were presented only for the small axis of the focal spot; both the small and the large axes results are given for the order of the fitted super-Gaussian profile. According to this measure-

Table 2. Focal Spot Analyses from Photometry and Interferometry with the 99-0148 Prototype

\begin{tabular}{lcc}
\hline \multicolumn{1}{c}{ Parameter } & $\begin{array}{c}\text { Photometric } \\
\text { Measurement }\end{array}$ & $\begin{array}{c}\text { Reconstruction } \\
\text { from Stitching }\end{array}$ \\
\hline $\begin{array}{l}\text { Ellipticity } \\
\text { Diameter (small axis) at } \\
1 / e I_{0}(\mu \mathrm{m})\end{array}$ & 0.83 & 0.81 \\
$\begin{array}{l}\text { Diameter (small axis) at 10\% } \\
I_{0}(\mu \mathrm{m})\end{array}$ & 372 & 307 \\
$\begin{array}{l}\text { Diameter (small axis) at } \\
3 \% I_{0}(\mu \mathrm{m})\end{array}$ & 446 & 372 \\
Order (small axis-large axis) & $5-7.5$ & 407 \\
\hline
\end{tabular}

ment, the prototype phase plate is in agreement with specifications at $1 / e, 10 \%$ of $I_{0}$, and at $3 \%$ of $I_{0}$. A super-Gaussian profile of the order of 4.5 is was also achieved for the small axis and 9.6 for the large axis.

\section{B. Stitching Interferometry}

Interferometry measurements of large optical components for laser applications such as the LIL and the LMJ require the use of an installation that responds to two main constraints:

The disposal of a large pupil adapted to the measurement of the full pupil of the component $(600-\mathrm{mm}$ diameter in our case) on one side.

A high spatial resolution to resolve the small period defects that are close to a millimeter.

We have studied stitching interferometry ${ }^{15}$ for several years. ${ }^{16,17}$ The technique offers a simple, economical, and usable solution compared with that of large interferometers. Its principle is quite simple. If a component is too large to be measured on its whole clear aperture on an interferometer, the measurement decomposed into a subaperture. The wave front is then reconstructed by numerical combination of the subaperture measurement by use of recovery areas. Despite some minor constraints, this subaperture metrology offers a higher resolution and dynamic than its large pupil equivalent. ${ }^{18,19}$ For these reasons, we chose to use a stitching interferometer to measure the wave front of 99-0148 prototype the phase plate. The experimental setup consists of the following:

A ZYGO GPI XP HR interferometer that operates at $632.8 \mathrm{~nm}$. The interferometer was equipped with a 300-mm-diameter expander and with a transmission flat transmission reference plate $(300-\mathrm{mm}$ diameter, $<\lambda / 20$ p.v.) mounted on a piezohead. We also used a reflection reference plate made of Zerodur. This plate has the same characteristics as those of the TF plate and conducts to an interferometric cavity of a planeity inferior to $60 \mathrm{~nm}$ p.v., $10-\mathrm{nm}$ rms.

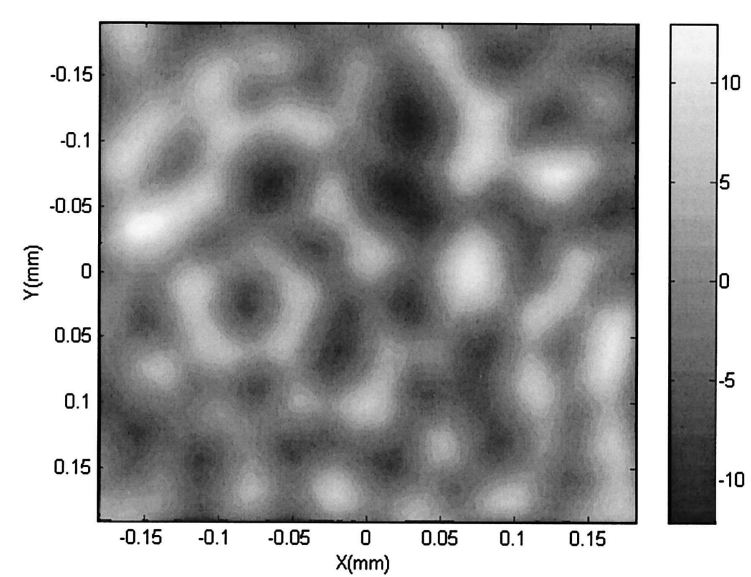

Fig. 7. Transmitted wave front of the 99-0148 prototype phase plate measured by use of stitching interferometry. 


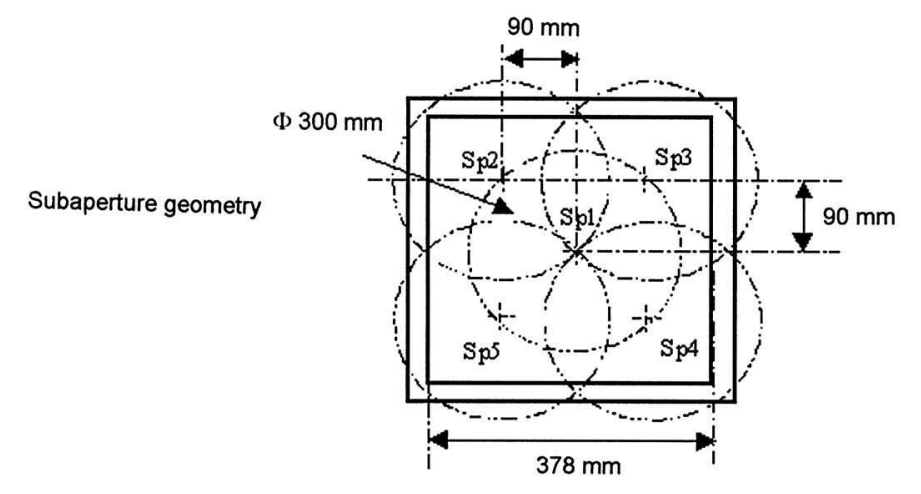

Subaperture interferograms

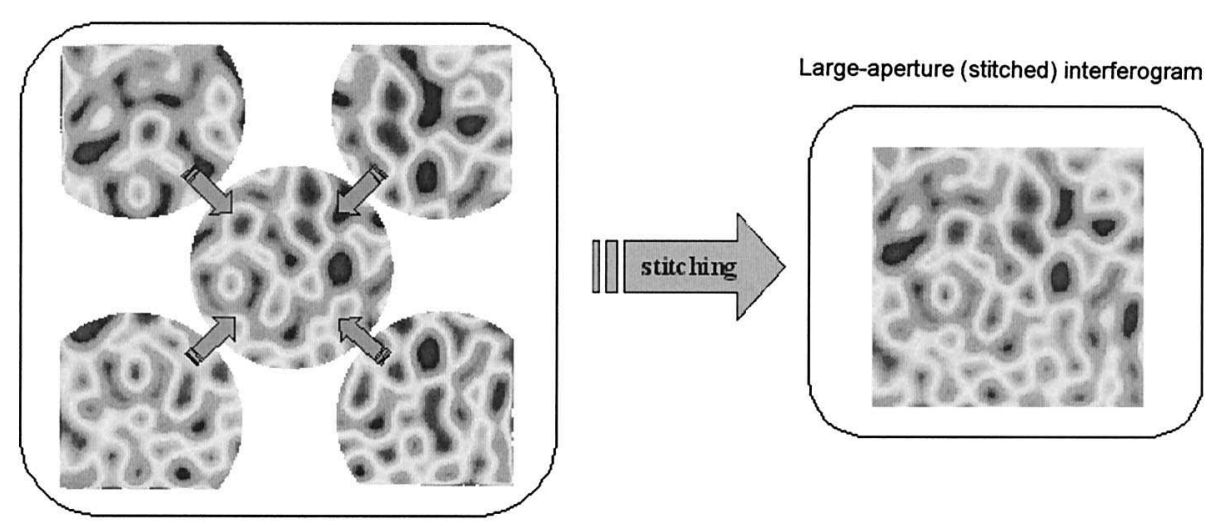

Fig. 8. Illustration of stitching interferometry showing a five-aperture configuration.

An $X-Y$ scanning mechanical device that allowed the measured component to be shifted in the interferometric cavity. The maximum displacement allowed is $1 \mathrm{~m}$ and the precision is inferior to $1 \mathrm{~mm}$.

A stitching software named Michael Bray Stitching Interferometer (MBSI) developed by MB Optique Company.

This experimental setup can be used for interferometric measurements with a repeatability of some nanometers owing to phase shifting and a sampling rate of $0.7 \mathrm{~mm}$. The setup is optimal for the measurement of phase plates with centimeter periods and a maximal slope inferior to $100 \mu \mathrm{rad}$. The transmitted wave front of the phase plate was measured with this stitching interferometer, which is presented in Fig. 7. The complete interferogram was reconstructed from the $300-\mathrm{mm}$ subaperture by use of the MBSI software as depicted in Fig. 8. The p.v. difference between the theoretical and the manufactured phase profile is measured at $22 \mathrm{~nm}$ for a p.v. of approximately $1.4 \mu \mathrm{m}$. The reproducibility of the stitching measurements is inferior to $10 \mathrm{~nm}$ p.v. and $0.2-\mathrm{nm}$ rms. Some measurements that were taken with six subapertures gave similar results.

The focal spot was reconstructed from the phase measurement by use of the method hereby detailed. If the phase plate were positioned just behind the focus grating, a simple Fourier transformation of the initial field would give the focal spot. In all the focal spot calculations it is important to take into account the actual phase-plate position, indeed the phase plate is $1.25 \mathrm{~m}$ from the focus grating. To include this constraint in our simulation we used the socalled adaptive diffraction: a mathematical transformation that allows for calculation of the field between the grating and the best-focus plane. ${ }^{20}$ Indeed the mesh simulation dimension decreased up to the focal plane. The results of the calculation performed on the phase plate measured by stitching interferometry is summarized in Table 2. Comparison between direct photometric focal spot measurements and reconstruction from stitching interferometry demonstrate good agreement of both metrology and the manufactured phase-plate component.

\section{Conclusion}

We have discussed the calculation of a phase plate for beam smoothing on power laser applications. A large $383 \mathrm{~mm} \times 398 \mathrm{~mm}$ phase plate was manufactured by Jobin Yvon. We have demonstrated that, by a combination of direct focal spot photometric measurements and focal spot calculations with a stitching interferogram, the component is in agreement with our needs. Stitching interferometry appears to be a versatile and useful method for this type of optical component.

We acknowledge G. de Villele, Y. Josserand, J. Flamand, and all the Jobin Yvon LIL and LMJ manufacturing team for their enthusiasms and continuous effort during the development and production of LIL 
phase plates. We also acknowledge M. Bray, MB Optique, for his collaboration, availability, and his specific developments with the MBSI software for our application.

\section{References}

1. M. L. André, "Status of the LMJ project," in Solid State Lasers for Application to Inertial Confinement Fusion: Second Annual International Conference, M. L. André, ed., Proc. SPIE 3047, 38-42 (1996).

2. W. H. Lowdermilk, "Status of the National Ignition Facility project," in Solid State Lasers for Application to Inertial Confinement Fusion: Second Annual International Conference, M. L. André, ed., Proc. SPIE 3047, 16-37 (1996).

3. Y. Kato, K. Mima, N. Miyanaga, S. Arinaga, Y. Kitagawa, M. Nakatsuka, and C. Yamanaka, "Random phasing of highpower lasers for uniform target acceleration and plasmainstability suppression,” Phys. Rev. Lett. 53, 1057-1060 (1984).

4. R. H. Lehmberg, A. J. Schmitt, and S. E. Bodner, "Theory of induced spatial incoherence,” J. Appl. Phys. 62, 2680-2701 (1987).

5. S. Skupsky, R. W. Short, T. Kessler, R. S. Craxton, S. Letzring, and J. M. Soures, "Improved laser-beam uniformity using the angular dispersion of frequency-modulated light," J. Appl. Phys. 66, 3456-3462 (1989).

6. A. Adolf, A. C. Boscheron, A. Dulac, and E. Journot, "Final optics design for the megajoule laser," in Third International Conference on Solid State Lasers for Application to Inertial Confinement Fusion, W. H. Lowdermilk, ed., Proc. SPIE 3492, 44-50 (1999).

7. J. Flamand, G. de Villèle, Y. Josserand, F. Bonnemason, B. M. Touzet, and J. Néauport, "Development of large aperture $1 \omega$ and $3 \omega$ gratings for the LIL laser," in Large Lenses and Prisms, R. G. Bingham and D. D. Walker, eds., Proc. SPIE 4411, 190196 (2001).

8. J. Néauport, P. Bouchut, J. Flamand, G. de Villèle, Y. Josserand, F. Bonnemason, B. M. Touzet, P. Garrec, X. Ribeyre, and G. Chabassier, "Large transmission $1 \omega$ and $3 \omega$ gratings for the LIL laser," in Physics, Theory, and Applications of Periodic Structures in Optics, P. Lalanne, ed., Proc. SPIE 4438, 41-50 (2001).

9. B. W. Woods, I. M. Thomas, M. A. Henesian, S. N. Dixit, and
H. T. Powell, "Large-aperture (80-cm diameter) phase plates for beam smoothing on Nova," in Solid State Lasers II, G. Dube, ed., Proc. SPIE 1410, 47-54 (1991).

10. S. N. Dixit, I. M. Thomas, B. W. Woods, A. J. Morgan, M. A. Henesian, P. J. Wegner, and H. T. Powell, "Random phase plates for beam smoothing on the Nova laser," Appl. Opt. 32, 2543-2554 (1993).

11. I. Thomas, S. N. Dixit, and M. C. Rushford, "Kinoform phase plates for focal plane irradiance profile control," Opt. Lett. 19, 417-419 (1994).

12. I. M. Thomas, S. N. Dixit, and M. C. Rushford, "Preparation of random-phase plates for laser-beam smoothing," in LaserInduced Damage in Optical Materials: 1994, H. E. Bennett, A. H. Guenther, M. R. Kozlowski, B. E. Newnam, and M. J. Soileau, eds., Proc. SPIE 2428, 264-270 (1994).

13. "Distributed phase plates for super-Gaussian focal-plane irradiance profiles," LLE (Laboratory for Laser Energetics) Rev. 63, 126-129 (1995).

14. R. W. Gerchberg and W. O. Saxton, "A practical algorithm for determination of phase from image and diffraction plane pictures," Optik 35, 237-246 (1972).

15. J. Tsujiuchi, M. Otsubo, and K. Okada, "Measurement of large plane surfaces shapes by connecting small-aperture interferograms," Opt. Eng. 33, 608-630 (1994).

16. M. Bray, "Stitching interferometer for large optics: recent developments of a system," in Third International Conference on Solid State Lasers for Application to Inertial Confinement Fusion, W. H. Lowdermilk, ed., Proc. SPIE 3492, 946-956 (1998).

17. M. Bray, "Stitching interferometry: how and why it works," in Optical Fabrication and Testing, R. Geyl and J. Maxwell, eds., Proc. SPIE 3739, 259-273 (1999).

18. M. Bray and A. Roussel, "Using first principles in the specifying of optics for large high-power lasers (I): application to the Megajoule laser (LMJ)," in Specification, Production, and Testing of Optical Components and Systems, A. E. Gee and J. Houee, eds., Proc. SPIE 2775, 328-344 (1996).

19. M. Bray, "Stitching interferometry: side effects on PSD," in Optical Manufacturing and Testing III, H. P. Stahl, ed., Proc. SPIE 3782, 443-452 (1999).

20. J. A. Fleck, J. R. Morris, and M. D. Feit, "Time-dependent propagation of high energy laser beams through the atmosphere," Appl. Phys. 10, 129-160 (1976). 